\title{
Childhood socioeconomic status modifies the association between intellectual abilities at age 20 and mortality in later life
}

\author{
E Kajantie, ${ }^{1,2}$ K Räikkönen, ${ }^{3}$ M Henriksson, ${ }^{4,5}$ T Forsén, $^{6,7} \mathrm{~K}$ Heinonen, ${ }^{3}$ \\ A K Pesonen, ${ }^{2,3} \mathrm{~J}$ T Leskinen, ${ }^{8}$ I Laaksonen, ${ }^{4}$ M Paile-Hyvärinen, ${ }^{1}$ C Osmond, ${ }^{9}$ \\ D J P Barker, ${ }^{9,10} \mathrm{~J} \mathrm{G} \mathrm{Eriksson}{ }^{1,6,7,11}$
}

\begin{abstract}
${ }^{1}$ National Institute for Health and Welfare, Helsinki, Finland ${ }^{2}$ Hospital for Children and Adolescents, Helsinki University Central Hospital, Helsinki, Finland

${ }^{3}$ Department of Psychology, University of Helsinki, Helsinki, Finland

${ }^{4}$ Centre for Military Medicine, Finnish Defence Forces, Lahti, Finland

${ }^{5}$ National Supervisory Authority for Welfare and Health, Helsinki, Finland

${ }^{6}$ Department of General Practice and Primary Health Care,

University of Helsinki, Helsinki, Finland

${ }^{7}$ Vasa Central Hospital, Vasa, Finland

${ }^{8}$ National Defence College, Finnish Defence Forces, Helsinki, Finland

${ }^{9}$ MRC Epidemiology Resource Centre, University of Southampton, General Hospital, Southampton, UK

${ }^{10}$ Heart Research Center Oregon Health and Science University,

Portland, Oregon, USA

${ }^{11}$ Helsinki University Central

Hospital, Unit of General

Practice, Helsinki, Finland
\end{abstract}

Correspondence to

E Kajantie, National Institute for Health and Welfare, PL 30 , Helsinki 00271, Finland; eero.kajantie@helsinki.fi

Accepted 24 August 2009 Published Online First 11 October 2009

\section{ABSTRACT \\ Background People who score poorly in intellectual ability tests have shorter life expectancy. A study was undertaken to determine whether this association is different in people from different socioeconomic backgrounds.}

Methods The mortality of 2786 men born in Helsinki, Finland during 1934-1944 who, as military conscripts, underwent a standardised intellectual ability test comprising verbal, visuospatial and arithmetic reasoning subtests was studied. Mortality data came from the Finnish Death Register.

Results Comparing men in the lowest and highest test score quartiles, HRs for all-cause mortality were 1.9 (95\% Cl 1.4 to 2.5) for verbal reasoning, 2.2 (95\% Cl 1.6 to 3.0$)$ for visuospatial reasoning and $1.9(95 \% \mathrm{Cl} 1.4$ to 2.5) for arithmetic reasoning, corresponding to 2.6, 3.4 and 2.6 excess years of life lost, respectively. Associations were similar for cardiovascular and noncardiovascular mortality. Intellectual ability scores were stronger predictors in men who grew up in middle-class families. Compared with middle-class men in the highest quartile of the visuospatial reasoning score, middle-class men in the lowest quartile lost 6.5 years of life while men from families of manual workers in the highest quartile lost 2.8 years and men in the lowest quartile lost 5.6 years.

Conclusions High intellectual ability in men aged 20 protects them from mortality in later life. This effect is stronger in men who grew up in middle-class families than in those who grew up in manual worker families. This finding suggests that early life conditions that are unfavourable to the development of cognitive abilities negate the life expectancy benefits of being born into a more affluent family.

\section{INTRODUCTION}

People who gain lower scores in intelligence tests have shorter lives. Although this phenomenon has been known for decades, ${ }^{1}$ only recently have longitudinal studies been able to link low premorbid intellectual ability with increased mortality and morbidity later in life. ${ }^{2-14}$

Why intellectual ability predicts mortality is only partly understood. Confounding by childhood socioeconomic status (SES), a strong predictor of mortality, ${ }^{3} 58915$ explains only a small proportion of the relationship. ${ }^{2} 3^{7-9} 12$ Although higher intellectual ability scores are associated with healthier adult lifestyle $e^{12} 14{ }^{16-18}$ and lower levels of risk factors for specific disorders, ${ }^{6} 1819$ data addressing cause-specific mortality and morbidity are inconclusive. Most published studies rely on childhood intelligence assessment; we are aware of only three longitudinal studies that have been able to use intellectual ability measured in early adulthood, when intellectual abilities are stronger predictors of adult outcomes such as educational attainment and occupational success. ${ }^{20} 21$ In studies of Swedish conscripts ${ }^{7} 10$ and Australian military recruits, ${ }^{13}$ follow-up was restricted to 51 and 40 years of age, respectively. Only a US Vietnam veterans study ${ }^{6}{ }^{14}$ has a follow-up to around 60 years. Furthermore, to our knowledge, no study has assessed whether the effects of intellectual ability on adult mortality differ among people of different socioeconomic backgrounds.

Our aim was to assess whether intellectual ability measured in male conscripts predicted mortality and whether this effect was different in men from different socioeconomic backgrounds.

\section{METHODS}

\section{Subjects}

The study population was from the Helsinki Birth Cohort which includes 8760 subjects (4630 men and 4130 women) who were born at Helsinki University Central Hospital between 1934 and 1944 and who attended child welfare clinics in Helsinki. School healthcare records were available for most participants. The cohort and data available have been described in detail elsewhere. ${ }^{22-24}$ Permission was obtained to link data collected within the Helsinki Birth Cohort Study (HBCS) with data from compulsory military service for these 4630 men, of whom 2786 (60.2\%) had intellectual ability test data.

We defined childhood SES based on the father's occupation which was obtained primarily from school healthcare records (77.3\%); if unavailable, child welfare clinic $(19.8 \%)$ or birth records $(1.1 \%)$ were used (data missing from all records for 1.8\%). The occupations were grouped into middle-class (comprising lower and higher officials and selfemployed people) and manual workers based on a classification from Statistics Finland.

Data for each subject's completed education, occupational and marital status have been received from Statistics Finland at 5-yearly intervals between 1970 and 2000. Maximum achieved education
This paper is freely availa unlocked scheme, see http:// jech.bmj.com/site/about/ unlocked.xhtml 
was grouped into four groups according to the UNESCO classification and maximum achieved occupation into four groups based on a classification used by Statistics Finland. Data for household taxable income came from Statistics Finland, based on the 1980 census.

The HBCS has been approved by the ethics committee of the National Public Health Institute and military service data were linked with permission from the Finnish Defence Command.

\section{Assessment of intellectual ability at the start of military service} The Finnish Defence Forces basic ability test was developed at the Finnish Defence Forces Education Development Centre. This obligatory test was introduced in different army regiments from 1955 onwards and was given to new recruits during the first 2 weeks of service. The test comprises verbal, visuospatial and arithmetic subtests, each composed of 40 multiple-choice questions increasing in difficulty, and has been described in detail elsewhere. ${ }^{24} 25$ Briefly, in the verbal reasoning subtest, the subject chooses synonyms, antonyms or words belonging or not belonging to the same category as given words, and similar relationships between two word pairs. In the arithmetic reasoning subtest, the subject completes series of numbers, solves short problems, computes simple arithmetic operations and chooses similar relationships between two pairs of numbers. The visuospatial reasoning task is analogous to the widely used Raven's Progressive Matrices ${ }^{26}$ and consists of a set of matrices with one removed part. The subject is asked to decide which of the given single figures completes the matrix. We used scores of individual tasks rather than a global total score because these scores may have dissimilar origins during development ${ }^{24}$ and different predictive values on disease. ${ }^{25}$ The test results for each subject were collected from microfilms of the Finnish Defence Forces Education Development Centre. The data also included the subject's height and weight. Body mass index (BMI) was calculated as $\mathrm{kg} / \mathrm{m}^{2}$.

\section{Mortality data}

A unique personal identification number was assigned to every resident of Finland by 1971. Using this number, we followed up the subjects from 1 January 1971 to 31 December 2003 by linking their birth data to the Finnish National Death Register. ${ }^{27}$ The primary causes of death were classified into disease categories (table 1) according to the International Classification of Diseases 8 (ICD-8) (until 1986), ICD-9 (1987-96) or ICD-10 (from 1997 onwards). Our main focus was on all-cause, cardiovascular and non-cardiovascular mortality.

\section{Data analysis}

A $\chi^{2}$ test was used to compare distributions of variables in categories, $\mathrm{t}$ test for comparison of continuous variables between groups and linear regression to assess the associations between continuous variables. The ability test results were converted to $\mathrm{z}$ scores (SD units) so that the mean $z$ score of the study cohort was zero. We examined these $z$ scores as predictors of mortality using Cox proportional hazards model, stratified according to year of birth. The verbal reasoning test $z$ scores increased by 0.05 z scores (95\% CI 0.04 to 0.06 ) per year of testing, visuospatial test z scores by 0.04 (95\% CI 0.03 to 0.05$)$ units and arithmetic test $z$ scores by 0.05 (95\% CI 0.04 to 0.07 ). The mean (SD) age at testing was 20.1 (1.4) years (range 17.0-28.1). An increase of 1 year in the age at testing was associated with an increase of 0.15 (95\% CI 0.12 to 0.17$)$ units in the verbal reasoning test z score, 0.12 (95\% CI 0.09 to 0.14 ) units in the visuospatial test $z$ score and 0.14 (95\% CI 0.11 to 0.17$)$ units in the arithmetic
Table 1 Comparison of men with intellectual ability test data available with the remaining source cohort

\begin{tabular}{|c|c|c|}
\hline \multicolumn{3}{|l|}{ Availability of intellectual ability test data } \\
\hline & $\begin{array}{l}\text { Data } \\
\text { available }\end{array}$ & $\begin{array}{l}\text { No data } \\
\text { available }\end{array}$ \\
\hline & $2786(100 \%)$ & $1844(100 \%)$ \\
\hline \multicolumn{3}{|l|}{ Year of birth } \\
\hline 1934 & $11(0.4 \%)$ & $153(8.3 \%)$ \\
\hline 1935 & $84(3.0 \%)$ & $90(4.9 \%)$ \\
\hline 1936 & $127(4.6 \%)$ & $103(5.6 \%)$ \\
\hline 1937 & $136(4.9 \%)$ & $97(5.3 \%)$ \\
\hline 1938 & $146(5.2 \%)$ & $138(7.5 \%)$ \\
\hline 1939 & $185(6.6 \%)$ & $132(7.2 \%)$ \\
\hline 1940 & $246(8.8 \%)$ & $176(9.5 \%)$ \\
\hline 1941 & $375(13.5 \%)$ & $261(14.2 \%)$ \\
\hline 1942 & $343(12.3 \%)$ & $164(8.9 \%)$ \\
\hline 1943 & $463(16.6 \%)$ & $231(12.5 \%)$ \\
\hline 1944 & $670(24.0 \%)$ & $299(10.8 \%)$ \\
\hline \multicolumn{3}{|l|}{ Father's occupational status } \\
\hline Manual worker & $1721(61.8 \%)$ & $1127(61.1 \%)$ \\
\hline Middle class & $1014(36.4 \%)$ & $671(36.4 \%)$ \\
\hline Unknown & $51(1.8 \%)$ & $46(2.5 \%)$ \\
\hline \multicolumn{3}{|l|}{ Mean (SD) body size at start of military service } \\
\hline Height $(\mathrm{cm})$ & $176.4(6.2)$ & $176.1(6.1)$ \\
\hline Body mass index $\left(\mathrm{kg} / \mathrm{m}^{2}\right)$ & $22.0(2.5)$ & $22.0(2.4)$ \\
\hline \multicolumn{3}{|l|}{ Highest education achieved } \\
\hline Basic or less & $1064(38.2 \%)$ & $702(38.1 \%)$ \\
\hline Upper secondary & $715(25.7 \%)$ & $426(23.1 \%)$ \\
\hline Lower tertiary & $607(21.8 \%)$ & $363(19.7 \%)$ \\
\hline Upper tertiary & $335(12.0 \%)$ & $223(12.1 \%)$ \\
\hline Unknown & $65(2.3 \%)$ & $130(7.0 \%)$ \\
\hline Dead in 2003 & $431(15.5 \%)$ & $388(21.0 \%)$ \\
\hline $\begin{array}{l}\text { Dead from cardiovascular disease (ICD } 390-459 \text {; } \\
\text { I00-199) }\end{array}$ & $143(5.1 \%)$ & $122(6.6 \%)$ \\
\hline Coronary heart disease (ICD 410-414; I21-I25) & $89(3.2 \%)$ & $73(4.0 \%)$ \\
\hline Stroke (ICD 430-438; I60-169) & $19(0.7 \%)$ & $18(1.0 \%)$ \\
\hline Dead from non-cardiovascular causes & $283(10.2 \%)$ & $261(14.2 \%)$ \\
\hline Dead from cancer (ICD 140-209; C00-C99) & $77(2.8 \%)$ & $77(4.2 \%)$ \\
\hline Mean (SD) age at death (years) & $51.7(7.7)$ & $50.6(10.3)$ \\
\hline
\end{tabular}

Cause of death unknown for five men with intellectual ability test data available and five men with data not available.

reasoning test $z$ score. We therefore adjusted all HRs for year and the age of subject at testing. We also performed additional adjustments for height, BMI and childhood and adult SES. From the HRs, we also calculated excess years of life lost by comparing life expectancy between the groups. Life expectancy was based on the Finnish year 2005 life tables, obtained from Statistics Finland, for men aged $26-70$ years (the period representing the range of follow-up in the present study). We divided the ability test scores into quartiles to illustrate the graded nature of the relationships; for trends of HRs, the scores were used as continuous variables. Interactions were assessed by including a product term in the model.

\section{RESULTS}

\section{Availability of intellectual ability test data}

We first compared those 2786 men for whom intellectual ability test data were available with the 1844 men for whom data were not available. Table 1 shows that more of the men born in the later years had available data. Availability of the ability test data was not related to father's occupational status $(p=0.1)$, body size during military service $(p \geq 0.2)$ or maximum achieved education $(p=0.4)$ later in life. Men who had no intellectual 
ability test data had a higher all-cause mortality (HR 1.4; 95\% CI 1.2 to 1.6 , adjusted for childhood SES and adult educational attainment) as well as cardiovascular mortality (HR 1.3; 95\% CI 1.0 to 1.7), non-cardiovascular mortality (HR 1.4; 95\% CI 1.2 to 1.7 ) and cancer mortality (HR 1.5; 95\% CI 1.1 to 2.1). For 3781 men $(81.7 \%)$ data were available on health screening at recruitment, 3585 of whom (94.8\%) had been classified as having adequate health for military service. When we restricted the analysis to these subjects, the men with no intellectual ability test data no longer had higher mortality.

\section{Intellectual ability, childhood socioeconomic status and body size}

Mean verbal reasoning $z$ scores were -0.20 and 0.35 in men from manual worker and middle-class families, respectively $(r=0.27)$; the corresponding mean $\mathrm{z}$ scores were -0.16 and $0.27(\mathrm{r}=0.21)$ for visuospatial tests and -0.18 and $0.31(r=0.24)$ for arithmetic tests (all $\mathrm{p}<0.0001)$. Taller men had higher scores: an increase in height of $10 \mathrm{~cm}$ was associated with an increase in $z$ scores of 0.24 (95\% CI 0.18 to 0.30 ) for verbal reasoning tests, 0.23 (0.17-0.29) for visuospatial tests and 0.22 (95\% CI 0.16 to 0.28$)$ for arithmetic reasoning tests. An increase in BMI of $5 \mathrm{~kg} / \mathrm{m}^{2}$ was related to an increase in the arithmetic z score of $0.09(95 \%$ CI 0.01 to 0.16 ) but not to the other scores.

\section{Intellectual ability and mortality}

Of the 2786 men, 431 (15.5\%) had died by the end of year 2003. Their causes of death and mean ages at death are shown in table 1.
Table 2 shows the HRs for mortality according to categories of the three intellectual ability subscales. Table 2 (model 1) shows that HRs for all-cause mortality increased progressively as the scores on each of the three tests fell. Because the increase seemed to be steepest between the highest test scores, we also tested for a quadratic relationship. p Values for the squared term were 0.06 for verbal, 0.05 for visuospatial and 0.07 for arithmetic reasoning test scores.

Table 2 also shows the associations between intellectual ability and cardiovascular and non-cardiovascular mortality. Mortality from both causes increased with lower intellectual ability scores. The only quadratic relationship was an inverse Ushaped association between non-cardiovascular mortality and visuospatial reasoning $(p=0.03)$. In addition, we analysed the effects on cancer and non-natural deaths. The HRs for death from cancer associated with a reduction of 1 unit in the mean $z$ score were 1.30 (95\% CI 1.04 to 1.63) for verbal reasoning, 1.19 (95\% CI 0.95 to 1.49) for visuospatial reasoning and 1.27 (95\% CI 1.02 to 1.57$)$ for arithmetic reasoning. The corresponding figures for non-natural deaths were 1.09 (95\% CI 0.85 to 1.41), 1.22 (95\% CI 0.95 to 1.56$)$ and 1.29 (95\% CI 1.01 to 1.65$)$.

\section{Socioeconomic status as a potential confounder, moderator or mediator}

While adjustment for height and BMI during military service had little effect on the results, further adjustment for childhood SES as indicated by the father's occupation had a small attenuating effect (model 2, table 2). We then assessed whether the

Table 2 HRs $(95 \% \mathrm{Cl})$ for death in men in quartiles of the score of each ability test subscale

\begin{tabular}{|c|c|c|c|c|c|c|}
\hline & $\begin{array}{l}\text { Number of } \\
\text { deaths/subjects }\end{array}$ & Verbal & $\begin{array}{l}\text { Number of } \\
\text { deaths/subjects }\end{array}$ & Visuospatial & $\begin{array}{l}\text { Number of } \\
\text { deaths/subjects }\end{array}$ & Arithmetic \\
\hline \multicolumn{7}{|c|}{ All-cause mortality } \\
\hline Lowest & $130 / 656$ & $1.9(1.4$ to 2.5$)$ & $135 / 674$ & 2.2 (1.6 to 3.0$)$ & $141 / 697$ & $1.9(1.4$ to 2.5$)$ \\
\hline 3 & $91 / 664$ & $1.3(1.0$ to 1.8$)$ & $120 / 849$ & $1.5(1.1$ to 2.1$)$ & $103 / 727$ & $1.4(1.0$ to 1.8$)$ \\
\hline Highest & $77 / 741$ & 1.0 (Referent) & $59 / 632$ & 1.0 (Referent) & $72 / 669$ & 1.0 (Referent) \\
\hline \multicolumn{7}{|c|}{ Per 1 unit lower z score } \\
\hline Model 3 & & $1.11(1.00$ to 1.24$)$ & & 1.18 (1.06 to 1.31$)$ & & 1.07 (0.96 to 1.19$)$ \\
\hline \multicolumn{7}{|c|}{ Cardiovascular mortality } \\
\hline Lowest & $36 / 656$ & $1.8(1.1$ to 3.1$)$ & $46 / 674$ & $2.3(1.3$ to 4.0$)$ & $44 / 697$ & $1.7(1.0$ to 2.8$)$ \\
\hline 2 & $50 / 724$ & $2.2(1.3$ to 3.7$)$ & $39 / 631$ & 2.1 (1.2 to 3.6$)$ & $39 / 676$ & $1.5(0.9$ to 2.5$)$ \\
\hline 3 & $34 / 664$ & 1.7 (1.0 to 2.9$)$ & $39 / 849$ & $1.5(0.9$ to 2.6$)$ & $33 / 727$ & $1.2(0.7$ to 2.1$)$ \\
\hline Model 3 & & $1.00(0.83$ to 1.22$)$ & & $1.18(0.98$ to 1.41$)$ & & $0.97(0.81$ to 1.17$)$ \\
\hline \multicolumn{7}{|c|}{ Non-cardiovascular mortality } \\
\hline Lowest & $94 / 656$ & 1.9 (1.4 to 2.7$)$ & $88 / 674$ & 2.2 (1.5 to 3.2$)$ & $95 / 697$ & 2.0 (1.4 to 2.9$)$ \\
\hline 2 & $79 / 724$ & $1.5(1.0$ to 2.1$)$ & $74 / 631$ & $2.0(1.3$ to 2.9$)$ & $70 / 676$ & $1.5(1.0$ to 2.2$)$ \\
\hline 3 & $54 / 664$ & $1.1(0.8$ to 1.6$)$ & $80 / 849$ & 1.5 (1.0 to 2.2$)$ & $68 / 727$ & $1.4(1.0$ to 2.0$)$ \\
\hline Highest & $56 / 741$ & 1.0 (Referent) & $41 / 632$ & 1.0 (Referent) & $47 / 669$ & 1.0 (Referent) \\
\hline \multicolumn{7}{|c|}{ Per 1 unit lower z score } \\
\hline Model 1 & & 1.28 (1.14 to 1.44$)$ & & $1.30(1.16$ to 1.45$)$ & & $1.24(1.11$ to 1.39$)$ \\
\hline Model 2 & & $1.26(1.11$ to 1.42$)$ & & $1.26(1.11$ to 1.42$)$ & & 1.20 (1.06 to 1.35$)$ \\
\hline Model 3 & & 1.17 (1.03 to 1.34$)$ & & $1.18(1.03$ to 1.34$)$ & & 1.12 (0.98 to 1.28$)$ \\
\hline
\end{tabular}

Analyses are stratified for year of birth and adjusted for age and year at testing.

Model 1: adjusted for year and age at testing.

Model 2: adjusted as for model 1 plus childhood socioeconomic status and height and body mass index at start of military service.

Model 3: adjusted as for model 2 plus adult education. 
effects of intellectual ability on mortality are different in men from different socioeconomic backgrounds (table 3). Although intellectual ability predicted mortality in men from both socioeconomic groups as defined by father's occupation, the relationship was stronger in men from middle-class families than in men from manual worker families ( $p$ values for interaction between childhood SES and intellectual ability scores 0.06 for verbal score, 0.002 for visuospatial score and 0.02 for arithmetic score). Conversely, childhood SES was a strong predictor of mortality among men who had high intellectual ability test scores; for men with low scores, childhood SES was not related to mortality. The stronger association of ability test scores in men from higher socioeconomic background was seen for both cardiovascular and non-cardiovascular mortality (not shown).

We assessed adult SES as a potential mediator of the relationship. As a primary proxy we used adult educational attainment, which has been reported to be more strongly correlated with early life intellectual ability than other widely used indicators of SES such as occupation and income. ${ }^{20} 21$ Mean verbal reasoning $\mathrm{z}$ scores for people who had achieved basic, upper secondary, lower tertiary and upper tertiary education were $-0.38,-0.19,0.44$ and 0.87 , respectively $(r=0.44)$. Corresponding values for visuospatial reasoning were $-0.41,-0.12$, 0.50 and $0.70(\mathrm{r}=0.42)$, and for arithmetic reasoning -0.44 , $-0.17,0.52$ and $0.88(\mathrm{r}=0.48$ ) (all $\mathrm{p}<0.0001)$. Adjustment for adult educational achievements attenuated the relationships between intellectual ability and mortality (model 3, table 2). However, verbal and visuospatial test scores remained a statistically significant predictor of all-cause and non-cardiovascular mortality (table 2). There was no interaction between the effects of adult educational attainment and ability test scores on mortality. Ability test scores were also associated with adult occupational status ( $r=0.45,0.42,0.44$ for verbal, visuospatial and arithmetic reasoning) and income $(r=0.23,0.22$ and 0.25$)$ (all $\mathrm{p}<0.0001$ ). In addition to model 3 , we performed further adjustments by including adult occupational status and income in the model. This attenuated the results slightly (not shown). However, the interaction between the effects of childhood SES and visuospatial test scores remained statistically significant $(p=0.005)$ and, in men from middle-class families, visuospatial test scores predicted mortality (HR for 1 unit lower z score 1.38, 95\% CI 1.09 to 1.75 ).

We then assessed marital status as a potential mediator of the relationship. Three hundred and twenty-three men $(12.0 \%$ of those with data available) had never been married. They had lower scores in verbal $(-0.13$ vs $0.02 ; p=0.01)$, visuospatial $(-0.18$ vs $0.03 ; p<0.0001)$ and arithmetic reasoning tests $(-0.13$ vs $0.03 ; p=0.007$ ). Adjustment for marital status did not affect the association between intellectual ability scores and mortality.

\section{Excess years of life lost}

The HRs were converted to excess years of life lost. A reduction of 1 unit in the $z$ score for the verbal test was associated with 0.8 ( $95 \%$ CI 0.4 to 1.1 ) excess years of life lost compared with 0.9 ( $95 \%$ CI 0.6 to 1.3) for the visuospatial test score and 0.7 (95\% CI 0.4 to 1.0) for the arithmetic test score. The differences between the lowest and highest ability test score quartiles were 2.6 years for the verbal test score, 3.4 years for the visuospatial test score and 2.6 years for arithmetic test score. The interaction between childhood SES and intellectual ability test scores is shown in table 4.

\section{DISCUSSION}

We found that men whose intellectual ability test scores at age 20 were in the lowest quartile had approximately twofold higher mortality rates, corresponding to approximately 3 years reduction in lifespan compared with men in the highest quartile. This is consistent with previous studies assessing intellectual ability in children ${ }^{2-5} 89$ or young adult men. ${ }^{6} 7131428$ The mortality

Table 3 HRs $(95 \% \mathrm{CI})$ for all-cause mortality according to quartiles of intellectual ability test scores and father's occupational status

\begin{tabular}{|c|c|c|c|c|}
\hline & $\begin{array}{l}\text { Number of } \\
\text { deaths/subjects }\end{array}$ & Manual worker & $\begin{array}{l}\text { Number of } \\
\text { deaths/subjects }\end{array}$ & Middle class \\
\hline \multicolumn{5}{|l|}{ Verbal } \\
\hline Lowest & $99 / 501$ & $2.1(1.4$ to 3.0$)$ & $27 / 140$ & $2.1(1.3$ to 3.4$)$ \\
\hline 3 & $64 / 391$ & 1.7 (1.2 to 2.6$)$ & $25 / 256$ & $1.0(0.6$ to 1.7$)$ \\
\hline Highest & $36 / 314$ & $1.3(0.8$ to 2.0$)$ & $39 / 414$ & 1.0 (Referent) \\
\hline Per 1 unit lower test $z$ score & & $1.16(1.02$ to 1.30$)$ & & 1.38 (1.16 to 1.65$)$ \\
\hline \multicolumn{5}{|l|}{ Visuospatial } \\
\hline Lowest & $98 / 506$ & $3.1(1.9$ to 5.1$)$ & $33 / 155$ & $3.5(2.0$ to 6.2$)$ \\
\hline 2 & $84 / 425$ & $3.2(1.9$ to 5.2$)$ & $31 / 194$ & 2.7 (1.5 to 4.7$)$ \\
\hline 3 & $80 / 490$ & 2.6 (1.6 to 4.3$)$ & $39 / 346$ & $1.8(1.0$ to 3.1$)$ \\
\hline Highest & $37 / 300$ & $2.0(1.1$ to 3.4$)$ & $21 / 319$ & 1.0 (Referent) \\
\hline Per 1 unit lower test $z$ score & & 1.17 (1.04 to 1.31$)$ & & $1.53(1.29$ to 1.81$)$ \\
\hline Lowest & $106 / 523$ & 2.5 (1.6 to 3.8$)$ & $32 / 161$ & $2.6(1.5$ to 4.3$)$ \\
\hline 2 & $80 / 459$ & $2.2(1.4$ to 3.4$)$ & $28 / 207$ & 1.7 (1.0 to 2.8$)$ \\
\hline 3 & $68 / 427$ & 2.0 (1.3 to 3.2 ) & $34 / 286$ & 1.6 (0.9 to 2.6$)$ \\
\hline Highest & $42 / 302$ & $1.7(1.1$ to 2.8$)$ & $29 / 356$ & 1.0 (Referent) \\
\hline Per 1 unit lower test $z$ score & & $1.13(1.00$ to 1.26$)$ & & $1.36(1.13$ to 1.63$)$ \\
\hline Adjusted for educational attainment & & $1.03(0.91$ to 1.16$)$ & & $1.23(0.99$ to 1.53$)$ \\
\hline
\end{tabular}

$\mathrm{p}$ for interaction between childhood socioeconomic status and intellectual ability scores 0.06 for verbal test score, 0.002 for visuospatial test score and 0.02 for arithmetic test score, adjusted for age, year, height and body mass index and testing and childhood socioeconomic status.

Analyses are stratified for year of birth and adjusted for age, year, height and body mass index and testing and childhood socioeconomic status. 
Table 4 Excess years of life lost $(95 \% \mathrm{Cl})$ according to quartiles of visuospatial test score and father's occupational status

\begin{tabular}{lll}
\hline Visuospatial test score & Manual worker & Middle class \\
\hline Lowest & $5.6(2.5$ to 9.4$)$ & $6.5(2.9$ to 11.2$)$ \\
2 & $5.7(2.7$ to 9.6$)$ & $4.6(1.6$ to 8.8$)$ \\
3 & $4.4(1.8$ to 8.0$)$ & $2.3(0.2$ to 5.5$)$ \\
Highest & $2.8(0.4$ to 6.2$)$ & 0.0 (Referent) \\
\hline
\end{tabular}

Analyses are stratified for year of birth and adjusted for age, year, height and body mass index and testing and childhood socioeconomic status.

gradient operates across the whole range of intellectual ability test scores.

The novel finding in our study is that intellectual ability scores, while predicting mortality in men from all socioeconomic backgrounds, are much stronger predictors in men who come from a middle-class background than in those from manual worker families. Men from middle-class families whose visuopatial reasoning scores were in the lowest quartile of all men had a 3.5-fold higher mortality or a 6.5-year reduction in lifespan compared with middle class-men whose scores were in the highest quartile. The mortality rate among men whose visuospatial reasoning scores were in the lowest quartile was similar in men from middle-class and manual worker families. While high scores were also protective for men from manual worker families, this protection was weaker than in men from middleclass families. The results for verbal and arithmetic reasoning were similar although the mortality gradients were less steep. In short, having high intellectual abilities was more strongly protective in men from middle-class backgrounds, while higher SES in childhood did not protect men with low intellectual abilities. This is noteworthy because an association between childhood SES and later mortality has been consistently reported. ${ }^{3} 58915$

\section{Possible mechanisms}

A number of mechanisms have been proposed to explain the protective effects of higher intelligence. ${ }^{2}$ They include adult socioeconomic advantage and social capital, healthier lifestyle and better disease management. Consistent with previous observations, ${ }^{6}{ }^{12-14}$ we found that adjusting for educational attainment attenuated the associations between intellectual abilities and mortality. This may be because both are measurements of intelligence, or because educational attainment encapsulates important aspects of SES in later life, or both may apply. The association between lower intelligence and higher mortality was strong in men from middle-class families. Previous studies suggest that these men are more likely to experience downward social mobility ${ }^{29}$ which, in turn, is associated with increased mortality. ${ }^{30}$ However, the associations between intellectual ability and mortality remained sizeable, particularly in men from middle-class families in whom the associations with visuospatial reasoning remained even after further adjustment for adult occupation and income. This argues that that the association between intellectual abilities and mortality is not solely explained by adult SES.

Part of our findings may be explained by healthier lifestyle, as suggested by previous findings that more intelligent children and young adults have more healthy diets ${ }^{17}$ are physically more active ${ }^{17}$ smoke less ${ }^{12} 1418$ and drink less alcohol ${ }^{14} 1618$ in their later lives. A role for earlier detection and better management of disease is supported by our finding that men who have lower intellectual abilities are more likely to die from cancer, while previous studies suggest that they are as likely to be diagnosed with cancer. ${ }^{32}$
Intelligent people may live longer because intelligence is part of a combination of properties of an individual-'fitness' - that are present from early life onwards and are associated with good health and protection against disease in later life. ${ }^{21} 22 \quad 24 \quad 33$ Cognitive function may be more closely related to fitness in children in middle-class families than in the families of manual workers. The most common reasons for poor fitness and poor cognitive functioning may differ according to SES. Moreover, socioeconomic factors may buffer adverse early life events that would lead to poor cognitive abilities. Consequently, men from middle-class families who are in the lowest quartile of intellectual ability scores may represent a more severe end of the cognitive abilities and 'fitness' spectrum that are more refractory to the buffering effects of SES.

\section{Public health implications}

Despite allocations of resources, socioeconomic health disparities remain and in many societies are increasing. ${ }^{34}$ Recent studies suggest that intellectual abilities are comparable if not stronger ${ }^{15}$ predictors of mortality than socioeconomic factors. While intellectual abilities are associated with SES, our findings and most others ${ }^{7} 812$ show that childhood and/or adult SES explain only part of the association between intellectual abilities and mortality. Our findings further underscore the predictive value of intellectual abilities by showing that, in men with the lowest intellectual ability test scores and thus the highest mortality, childhood socioeconomic background had no additional effect on mortality beyond that predicted by intellectual abilities. For the long term, these findings add to the evidence that promoting optimal early development will both improve cognitive function and prolong life. In the shorter term, societal support to people with low intellectual abilities in taking responsibility over their health should be encouraged. Within the healthcare system, health education and patient information need to be tailored to meet the needs of people with different intellectual abilities.

\section{Strengths and limitations}

The strengths of this study include the intellectual ability test performed during compulsory military service in early adulthood and the near comprehensive availability of socioeconomic and validated ${ }^{27}$ mortality data through national registers. Intellectual ability tests performed around the age of 20 years are better predictors of adult education and occupation ${ }^{20}$ and intelligence $e^{35} 36$ than those performed in childhood. We have previously discussed the limitations of the HBCS. ${ }^{37}$ The most obvious limitations of the present study are that it is limited to men. Moreover, not all men in the HBCS underwent the intellectual ability test. The availability of intellectual ability data was, however, not associated with childhood SES or adult education, nor was it associated with mortality when men who were exempted from service because of health were excluded from the analysis.

\section{CONCLUSIONS}

Intellectual ability in young men is a strong predictor of mortality later in life. The association is observed for cardiovascular, non-cardiovascular and cancer mortality. While high intellectual ability is protective for men from all socioeconomic backgrounds, its protective effect is much stronger in men who grew up in middle-class families than in men from manual worker families. Conversely, the association between low SES in childhood and increased mortality is not seen in men with low intellectual ability scores. While the optimal period for 


\section{What is already known on this subject}

People who as children or young adults gain lower scores in intellectual ability tests have shorter life expectancy.

\section{What this study adds}

- The association between intellectual ability at age 20 and mortality is stronger in men who grew up in middle-class families than in those from manual worker families.

- When men from middle-class families who were in the highest quartile of visuospatial reasoning score were set as the reference, middle-class men in the lowest quartile lost on average 6.5 years of life, while men from manual worker families in the highest quartile lost 2.8 years and those in the lowest fourth lost 5.6 years.

promoting intellectual development may be very early in life, in the shorter term our results underscore the importance of empowerment of people in the lower end of the intellectual ability spectrum in today's society with its increasing demands for better intellectual performance.

Acknowledgements The authors are grateful to Sigrid Rosten, Hanna Alastalo and Terttu Nopanen who extracted the Finnish Defence Forces data from the microfilms. Sigrid Rosten was responsible for data management.

Funding This work was supported by the British Heart Foundation; the Academy of Finland; the Päivikki and Sakari Sohlberg Foundation; the Finnish Diabetes Research Foundation; the Finnish Foundation for Cardiovascular Research; the Finnish Foundation for Paediatric Research; the Finnish Medical Society Duodecim; the Jalmari and Rauha Ahokas Foundation; the Novo Nordisk Foundation; the Signe and Ane Gyllenberg Foundation; the Sigrid Jusélius Foundation; the Yrjö Jahnsson Foundation; the Juho Vainio Foundation; and Finska Läkaresällskapet.

\section{Competing interests None}

Ethics approval This study was conducted with the approval of the ethics committee of the National Public Health Institute.

Contributors EK generated the study questions, analysed the data, wrote the first draft of the manuscript, coordinated other authors' contributions to the redrafts and acts as a guarantor of the paper. KR contributed to the discussion and data analysis with her expertise in intellectual ability testing and to redrafts of the manuscript. MH has previously published a study using data from the same intellectual ability tests as predictors of psychiatric outcomes and contributed with this experience to the data analysis and writing of the Materials and Methods section and discussion. TF was responsible for the collection of data from the archives of Finnish Defence Forces and contributed to redrafts of the manuscript. $\mathrm{KH}$ and AKP contributed to the discussion with their expertise on psychological aspects of intellectual ability testing. JTL and IL are responsible for the development of the Finnish Defence Forces intellectual ability test; they oversaw the data collection and contributed to the interpretation of the results and the description of the test in the Materials and Methods section. MP-H took part in cleaning of the intellectual ability test data and contributed to the data analysis, description of the intellectual ability test results and discussion. CO took part in the design and implementation of the Helsinki Birth Cohort Study; as a statistical expert, he oversaw the data analysis and contributed to its description in the Materials and Methods section. DJPB took part in the design and implementation of the Helsinki Birth Cohort Study and contributed to the interpretation of the results, writing the cohort description in the Materials and Methods section and rewriting of the manuscript drafts as a whole. JGE was responsible for the design and implementation of the Helsinki Birth Cohort Study and linked the data with intellectual ability tests scores of the Finnish Defence Forces; he also contributed to data analysis and presentation and rewriting of the manuscript drafts.

Provenance and peer review Not commissioned; externally peer reviewed.

\section{REFERENCES}

1. Maller JB. Vital indices and their relation to psychological and social factors. Hum Biol 1933:5:94-121.

2. Batty GD, Deary IJ, Gottfredson LS. Premorbid (early life) IO and later mortality risk: systematic review. Ann Epidemiol 2007;17:278-88.

3. Whalley LJ, Deary IJ. Longitudinal cohort study of childhood IO and survival up to age 76. BMJ 2001;322:819

4. Pearce MS, Deary IJ, Young AH, et al. Childhood 10 and deaths up to middle age: The Newcastle Thousand Families Study. Public Health 2006;120:1020-6.

5. Batty GD, Der G, Macintyre S, et al. Does I0 explain socioeconomic inequalities in health? Evidence from a population based cohort study in the west of Scotland. BMJ 2006;332:580-4.

6. Batty GD, Gale CR, Mortensen LH, et al. Pre-morbid intelligence, the metabolic syndrome and mortality: the Vietnam Experience Study. Diabetologia 2008; 51:436-43

7. Hemmingsson $\mathbf{T}$, Melin $B$, Allebeck $P$, et al. The association between cognitive ability measured at ages 18-20 and mortality during 30 years of follow-up-a prospective observational study among Swedish males born 1949-51. Int J Epidemiol 2006;35:665-70.

8. Osler M, Andersen AM, Due P, et al. Socioeconomic position in early life, birth weight, childhood cognitive function, and adult mortality. A longitudinal study of Danish men born in 1953. J Epidemiol Community Health 2003:57:681-6.

9. Hart CL, Taylor MD, Davey Smith G, et al. Childhood IO, social class, deprivation, and their relationships with mortality and morbidity risk in later life: prospective observational study linking the Scottish Mental Survey 1932 and the Midspan studies. Psychosom Med 2003;65:877-83.

10. Hemmingsson T, v Essen J, Melin B, et al. The association between cognitive ability measured at ages 18-20 and coronary heart disease in middle age among men: a prospective study using the Swedish 1969 conscription cohort. Soc Sci Med 2007:65:1410-19.

11. Batty GD, Mortensen EL, Nybo Andersen AM, et al. Childhood intelligence in relation to adult coronary heart disease and stroke risk: evidence from a Danish birth cohor study. Paediatr Perinat Epidemiol 2005;19:452-9.

12. Kuh D, Richards M, Hardy R, et al. Childhood cognitive ability and deaths up until middle age: a post-war birth cohort study. Int J Epidemiol 2004;33:408-13.

13. O'Toole BI, Stankov L. Ultimate validity of psychological tests. Pers Individ Dif 1992;13:699-716.

14. Batty GD, Shipley MJ, Mortensen LH, et al. IO in late adolescence/early adulthood risk factors in middle age and later all-cause mortality in men: the Vietnam Experience Study. J Epidemiol Community Health 2008;62:522-31.

15. Roberts BW, Kuncel NR, Shiner $\mathrm{R}$, et al. The power of personality. The comparative validity of personality traits, socioeconomic status, and cognitive ability for predicting important life outcomes. Perspect Psychol Sci 2007;2:313-45.

16. Batty GD, Deary IJ, Macintyre S. Childhood IO and life course socioeconomic position in relation to alcohol induced hangovers in adulthood: the Aberdeen children of the 1950s study. J Epidemiol Community Health 2006;60:872-4.

17. Batty GD, Deary IJ, Schoon I, et al. Childhood mental ability in relation to food intake and physical activity in adulthood: the 1970 British Cohort Study. Pediatrics 2007:119:e38-45.

18. Batty GD, Deary IJ, Schoon I, et al. Mental ability across childhood in relation to risk factors for premature mortality in adult life: the 1970 British Cohort Study. J Epidemiol Community Health 2007:61:997-1003.

19. Starr JM, Taylor MD, Hart CL, et al. Childhood mental ability and blood pressure at midlife: linking the Scottish Mental Survey 1932 and the Midspan studies $J$ Hypertens 2004:22:893-7.

20. Strenze T. Intelligence and socioeconomic success: a meta-analytic review of longitudinal research. Intelligence 2007;35:401-26.

21. Neisser U, Boodoo G, Bouchard TJ, et al. Intelligence: knowns and unknowns. Am Psychologist 1996;51:77-101.

22. Eriksson JG, Forsén T, Tuomilehto J, et al. Early growth and coronary heart disease in later life: longitudinal study. BMJ 2001;322:949-53.

23. Barker DJ, Forsén T, Uutela A, et al. Size at birth and resilience to effects of poor living conditions in adult life: Iongitudinal study. BMJ 2001:323:1273-6.

24. Räikkönen K, Forsén T, Henriksson $M$, et al. Growth trajectories and intellectual abilities in young adulthood: The Helsinki Birth Cohort Study. Am J Epidemiol 2009:170:447-55.

25. Tiihonen J, Haukka J, Henriksson M, et al. Premorbid intellectual functioning in bipolar disorder and schizophrenia: results from a cohort study of male conscripts. Am J Psychiatry 2005;162:1904-10.

26. Raven J. The raven's progressive matrices: change and stability over culture and time. Cogn Psychol 2000:41:1-48.

27. Lahti RA, Penttilä A. The validity of death certificates: routine validation of death certification and its effects on mortality statistics. Forensic Sci Int 2001:115:15-32.

28. Silventoinen K, Modig-Wennerstad K, Tynelius P, et al. Association between intelligence and coronary heart disease mortality: a population-based cohort study of 682361 Swedish men. Eur J Cardiovasc Prev Rehabil 2007:14:555-60.

29. Deary IJ, Taylor MD, Hart CL, et al. Intergenerational social mobility and mid-life status attainment: Influences of childhood intelligence, childhood social factors, and education. Intelligence 2005;33:455-72.

30. Hart CL, Davey Smith G, Blane D. Social mobility and 21 year mortality in a cohort of Scottish men. Soc Sci Med 1998:47:1121-30. 
31. Næss $\emptyset$, Hernes FH, Blane D. Life-course influences on mortality at older ages: evidence from the Oslo Mortality Study. Soc Sci Med 2006;62:329-36.

32. Batty GD, Wennerstad KM, Smith GD, et al. IO in early adulthood and later cancer risk: cohort study of one million Swedish men. Ann Oncol 2007:18:21-8.

33. Kajantie E. Early life events. Effect on aging. Hormones 2008; 7:101-13.

34. Mackenbach JP, Stirbu I, Roskam AJ, et al. Socioeconomic inequalities in health in 22 European countries. N Engl J Med 2008;358:2468-81.
35. Deary IJ, Whalley LJ, Lemmon $\mathrm{H}$, et al. The stability of individual differences in mental ability from childhood to old age: Follow-up of the 1932 Scottish mental survey Intelligence 2000;28:49-55.

36. Kangas J, Bradway K. Intelligence at middle age: a thirty-eight-year follow-up. Dev Psychol 1971:5:333-7.

37. Ylihärsilä H, Kajantie E, Osmond C, et al. Birth size, adult body composition and muscle strength in later life. Int J Obes (Lond) 2007;31:1392-9. 